\title{
The relationship between peripheral muscle strength and respiratory function and respiratory muscle strength in athletes
}

\author{
Bihter Akınoğlu' ${ }^{1, *}$, Tuğba Kocahan² , Taşkın Özkan' \\ 'Department of Physiotherapy and Rehabilitation, Faculty of Health Sciences, Ankara Yıldırım Beyazıt University, Ankara, Turkey \\ 2Department of Health Services, Center of Athlete Training and Health Research, The Ministry of Youth and Sports, Sports General Directorship, Ankara, Turkey
}

The aim of this study is to determine the relationship between peripheral muscle strength, respiratory function and respiratory muscle strength in athletes. The study included a total of 150 elite athletes (judo, rowing, gymnastics) (age, $16.94 \pm 2.37$ years; length, $167.70 \pm 12.23 \mathrm{~cm}$; body weight, $62.87 \pm 17.33 \mathrm{~kg}$; body mass index, $\left.21.95 \pm 2.92 \mathrm{~kg} / \mathrm{m}^{2}\right)$. Isomed 2000 isokinetic dynamometer was used to assess peripheral muscle strength. The strength of the dominant side knee flexor and extensor muscles was evaluated at $60 \% \mathrm{sec}$ and $180 \% \mathrm{sec}$. At the end of the evaluation; knee flexion and extension peak torque (PT) values and flexion and extension PT values rates were obtained at $60 \%$ sec and $180 \%$ sec. Respiratory function and respiratory muscle strength of the athletes were evaluated using a digital spirometer. To assess respiratory function, forced vital capacity maneuver and maximal minute ventilation test; to assess the strength of the respiratory muscles, maximum inspi- ratory pressure and maximal expiratory pressure tests were performed. There was a strong relationship between muscle strength of knee flexor and extensor muscles and respiratory function $(r=-0.268 / 0.813$, $P<0.05)$. There was a strong moderate correlation between knee flexor and extensor muscle strength and all parameters of respiratory muscle strength $(r=0.206 / 0.411, P<0.05)$. The knee flexor and extensor muscle strength, respiratory function and respiratory muscle strength develops parallel to each other and the codevelopment of these parameters together with special exercises to increase respiratory muscle strength will improve the performance of the athletes.

Keywords: Athletes, Muscle strength, Respiratory muscle, Respiratory function

\section{INTRODUCTION}

Peripheral muscle strength, respiratory function and respiratory muscle strength are parameters effective in physical fitness level and healh (Arikan et al., 2015). The knee extensor and flexors from the peripheral muscles are the biggest, most blood-stained muscles in the body and so they need a great deal of oxygen (Saltin et al., 1998). At the same time, their effects on sports performance are quite high without distinguishing the branch (Saltin et al., 1998).

When we look at the studies evaluating the relationship between peripheral muscle strength and sportive performance; in the study of Soslu et al. (2016) on basketball athletes, it was con- cluded that maximal knee extensor strength is an important component in anaerobic and sprint performance (Soslu et al., 2016). In the study of Newman et al. (2004) on football; single sprint performance was associated with peak knee extensor and flexor torque at all speeds. In the study of Alexander (1989) in the elite sprinter; peak isokinetic concentric peak torque of the knee extensor muscles were found to be associated with 100-m performance. Moreover, in the study having been performed by Arslan (2005) on healthy young individuals, explosive leg strength was associated with anaerobic performance. As can be seen, it has been shown that lower extremity muscle strength is associated with performance in sports branches both aerobic and anaerobic systems are used dominantly.

\footnotetext{
*Corresponding author: Bihter Akınoğlu (D) https://orcid.org/0000-0002-8214-7895 Department of Physiotherapy and Rehabilitation, Faculty of Health Sciences, Ankara Yildırım Beyazıt University, Ankara, Turkey

E-mail: rgkardelen@yahoo.com

Received: October 22, 2018 / Accepted: December 21, 2018
}

This is an Open Access article distributed under the terms of the Creative Commons Attribution Non-Commercial License (http://creativecommons.org/licenses/by-nc/4.0/) which permits unrestricted non-commercial use, distribution, and reproduction in any medium, provided the original work is properly cited. 
When we examine the studies on respiratory function and respiratory muscle strength and performance; In the study of Salinero et al. (2016), it has been concluded that lung function in amateur runners was associated with marathon race duration and a high lung capacity may be an important variable for marathon performance of amateur runners. In the study of Nicks et al. (2009); they showed that respiratory muscle strength training has improved intermittent exercise performance in soccer players. In a study by Pringle et al. (2005) on runners, lung capacity was found to be related to $10-\mathrm{km}$ race performance. Also it has been shown that in high-level athletes, pulmonary volumes are higher than GLI-2012 values for the general population, both in reference to the age considered (12-35 years) and height (Appodia et al., 2018). In the light of these information in the literature, in our study we aimed to investigate the relationship between peripheral muscle strength and pulmonary function and respiratory muscle strength which having effects on performance in sports branches aerobic or anaerobic metabolism is dominantly used.

\section{MATERIALS AND METHODS}

The study was designed to investigate the relationship between peripheral muscle strength and respiratory function and respiratory muscle strength. The study included elite judo, rowing and gymnastics athletes from the Olympic Preparatory Center between 1 January-30 April 2017. The exclusion criteria were having been playing sports less than 3 years, having pain in the lower extremities in the last 6 months, having orthopedic problems in the lower extremities, an acute or chronic illness related to the respiratory system. Initially, 159 athletes were included in the study but 9 were excluded because they had the exclusion criteria. Thus, a total of 150 elite (national team) judo, shovel and gymnastics athletes, 84 male and 66 female, were enrolled the study. This study was designed according to the Declaration of Helsinki and the research protocol was approved by the Ankara Keçiören Research and Training Hospital Ethical Committee (approval number: 2012-KAEK-15/1611) before subject enrollment. All participants were fully informed about the study, and they all signed written informed consent.

\section{Evaluation}

\section{Evaluation of knee flexor and extensor muscle strength}

The dominant side knee flexor and extensor muscles strength of the athletes was assessed with an IsoMed 2000 isokinetic dynamometer (Ferstl, Germany). Before the test, the athletes were asked to jog for $10 \mathrm{~min}$. Tests were applied in sitting position. The athletes were stabilized on their shoulders with the shoulder apparatus and with stabilization straps over the lumbar region and distal femur. The pivot point is adjusted to be the lateral condyle of the femur. A few experiments were conducted before the tests to could understand the tests and adapt athletes to the tests. During the tests, the athletes were verbally encouraged. The strength of the knee flexors and extensor muscles was evaluated at angular velocities of $60 \% \mathrm{sec}$ and $180 \% \mathrm{sec}$. At the end of the evaluation; peak torque values at both angular velocities of the knee flexor and extender muscles and ratios of the flexion and extension peak torque values were obtained (Alemdaroğlu, 2012).

\section{Evaluation of respiratory function and respiratory muscle strength}

Respiratory function and respiratory muscle strength of the athletes were evaluated with a digital spirometer (Pony FX, Cosmed, Albano Laziale, Italy). The participants were informed about the tests before the evoluation. The athletes were asked to not eat anything at least $2 \mathrm{hr}$ and were rested for at least $15 \mathrm{~min}$ between each test. Tests were applied in a comfortable sitting position. During the tests the athlete's nose was latched. During the tests the athletes asked close their mouth without spaces in the mouth edges with his lips to prevent air from escaping from the mouth of the spirometry. Tests were performed by breathing maneuvers from the mouth of the spirometer. The athletes were conducted several trial before the test, to understand the tests and to be able to adapt to the device. Each test was performed 3 times and the best measurement score was used for statistical analysis (Miller et al., 2005; Sarsan et al., 2013).

In order to evaluate the respiratory functions of the athletes, forced vital capacity (FVC) maneuver and maximal minute ventilation (MVV) test were performed. During FVC maneuvers, the athlete was first asked to take a deep breath, and evacuate all the air in his lungs fast, strong and long when he came to the point that he could no longer breathe and then take a deep breath again. As a result of the test; FVC, forced expiratory volume in $1 \mathrm{sec}$ $\left(\mathrm{FEV}_{1}\right), \mathrm{FEV}_{1} / \mathrm{FVC}$, and peak expiratory flow were obtained. During the MVV test, the athletes was asked to breathe deeply, quickly and strongly for $12 \mathrm{sec}$. At the end of the test, the athletes asked to hold his breath for a few sec in order to avoid the respiratory alcoholism. The MVV value was obtained as the test result.

Maximum inspiratory pressure (MIP) and maximal expiratory pressure (MEP) tests were performed to assess the respiratory muscles strength. For the MIP test, the athlete was asked to ex- 
hale the air in his lungs completely then to breathe deeply, quickly and strongly. For the MEP test, the athlete was asked to inhale the air in his lungs completely then to exhale quickly, strongly and fully. As a result of the tests, MIP and MEP values were obtained (American Thoracic Society/European Respiratory Society, 2002; Evans and Whitelaw, 2009; Miller et al., 2005).

\section{Statistical analysis}

Statistical analysis was performed by using SPSS ver. 15.0 (SPSS Inc., Chicago, IL, USA). Visual (histogram, probability plots) and analytical methods (Kolmogorov-Smirnov test) were used to define whether the variables were normally distributed. In order to examine the relation between variables; Pearson correlation analy-

Table 1. Physical characteristics and sports ages of athletes $(n=150)$

\begin{tabular}{lcc}
\hline Variable & Mean \pm SD (range) & Median (IOR) \\
\hline Age $(\mathrm{yr})$ & $16.94 \pm 2.37(13-25)$ & $17(15-18)$ \\
Height $(\mathrm{cm})$ & $167.70 \pm 12.23(137-194)$ & $167.50(159-175)$ \\
Body weight $(\mathrm{kg})$ & $62.87 \pm 17.33(33-138)$ & $61(50-75)$ \\
Body mass index $\left(\mathrm{kg} / \mathrm{m}^{2}\right)$ & $21.95 \pm 3.76(15.07-41.21)$ & $21.87(19.38-23.67)$ \\
Sports Age $(\mathrm{yr})$ & $6.45 \pm 2.92(3-13)$ & $6.50(4-8)$ \\
\hline
\end{tabular}

$\mathrm{SD}$, standard deviation; IOR, interquartile range.

Table 2. Descriptive statistics of the knee flexor and extensor muscle strength of athletes $(n=150)$

\begin{tabular}{lcc}
\hline Variable & Mean \pm SD (range) & Median (IQR) \\
\hline $60^{\circ} /$ sec knee & & \\
Flexion PT & $94.57 \pm 35.84(23.80-189.90)$ & $88.60(68.10-117.90)$ \\
Extension PT & $178.07 \pm 62.76(41.80-329.80)$ & $175.70(125.10-225.10)$ \\
Flexion PT/extension PT & $53.43 \pm 8.77(32.80-102.90)$ & $52.85(47.40-58.70)$ \\
$180^{\circ} /$ sec knee & & \\
Flexion PT & $74.28 \pm 26.45(18.60-140.40)$ & $69.50(54.60-96.90)$ \\
Extension PT & $123.39 \pm 40.26(34.60-225.10)$ & $121.25(90.60-152.80)$ \\
Flexion PT/extension PT & $60.35 \pm 9.68(42.70-110.70)$ & $59.55(53.10-66.50)$ \\
\hline
\end{tabular}

SD, standard deviation; IQR, interquartile range; PT, peak torque. sis was used for numerical variables with normal distribution, and Spearman correlation analysis was used for variables with at least one ubnormal distribution. It was observed that PT values of the extensor movements at $180^{\circ} / \mathrm{sec}, \mathrm{FVC}, \mathrm{FEV}_{1}, \mathrm{MVV}$, and MIP values were normal distributions, while other knee flexors and extensor muscular strength, respiratory function and respiratory muscle strength test results were not distributed normally. Statistical error level was determined as $P<0.05$.

\section{RESULTS}

Physical characteristics and sports years of a total of 150 athletes, 84 male (56\%) and 66 female (44\%) included in the study are given in Table 1 . The descriptive statistics of the knee flexor and extensor muscle strength, respiratory function and respiratory muscle strength of the athletes are given in Tables 2 and 3. All parameters between the knee flexor and extensor muscle strength and respiratory function were found to be strongly related $(r=$ $-0.268 / 0.813, P<0.05$ ) (Table 4). When the relationship between the muscle strength of the knee flexor and the extensor muscles and respiratory muscle strength is examined, the parameters were

Table 3. Descriptive statistics of respiratory function and respiratory muscle strength of the athletes $(n=150)$

\begin{tabular}{lcc}
\hline Variable & Mean \pm SD (range) & Median (IOR) \\
\hline FVC (L) & $4.35 \pm 1.17(2.15-7.82)$ & $4.29(3.44-5.11)$ \\
FEV $_{1}(\mathrm{~L})$ & $3.72 \pm 0.93(1.82-6.37)$ & $3.67(2.99-4.35)$ \\
FEV $_{1} /$ FVC (\%) & $85.72 \pm 5.69(61.50-98.80)$ & $86(83-89.20)$ \\
PEF (L/sec) & $6.99 \pm 2.13(1.04-14.68)$ & $6.81(5.69-8.26)$ \\
MWV (L/min) & $133.62 \pm 40(49.60-254.40)$ & $126.05(107-164.80)$ \\
MIP (cmH $\left.\mathrm{cm}_{2} \mathrm{O}\right)$ & $110.52 \pm 29.68(49-236)$ & $109(90-129)$ \\
MEP $\left(\mathrm{cmH}_{2} \mathrm{O}\right)$ & $125.66 \pm 37.12(61-241)$ & $121(97-144)$ \\
\hline
\end{tabular}

SD, standard deviation; IQR, interquartile range; FVC, forced vital capacity; $F E V_{1}$, forced expiratory volume in $1 \mathrm{sec}$; PEF, peak expiratory flow; MW, maximal minute ventilation; MIP, maximum inspiratory pressure; MEP, maximal expiratory pressure.

Table 4. Relationship between knee flexor and extensor muscle strength and respiratory function $(n=150)$

\begin{tabular}{|c|c|c|c|c|c|c|c|c|c|c|}
\hline \multirow{2}{*}{ Variable } & \multicolumn{2}{|c|}{ FVC } & \multicolumn{2}{|c|}{$\mathrm{FEV}_{1}$} & \multicolumn{2}{|c|}{$\mathrm{FEV}_{1} / \mathrm{FVC}$} & \multicolumn{2}{|c|}{ PEF } & \multicolumn{2}{|c|}{ MVV } \\
\hline & $r$ & $P$-value & $r$ & $P$-value & $r$ & $P$-value & $r$ & $P$-value & $r$ & $P$-value \\
\hline \multicolumn{11}{|l|}{$60^{\circ} /$ sec knee } \\
\hline Flexion PT & 0.786 & 0.000 & 0.752 & 0.000 & -0.277 & 0.001 & 0.679 & 0.000 & 0.664 & 0.000 \\
\hline Extension PT & 0.784 & 0.000 & 0.752 & 0.000 & -0.278 & 0.001 & 0.710 & 0.000 & 0.703 & 0.000 \\
\hline \multicolumn{11}{|l|}{$180^{\circ} /$ sec knee } \\
\hline Flexion PT & 0.812 & 0.000 & 0.787 & 0.000 & -0.268 & 0.001 & 0.692 & 0.000 & 0.689 & 0.000 \\
\hline Extension PT & 0.813 & 0.000 & 0.800 & 0.000 & -0.284 & 0.000 & 0.736 & 0.000 & 0.742 & 0.000 \\
\hline
\end{tabular}

FVC, forced vital capacity; FEV 1 , forced expiratory volume in 1 sec; PEF, peak expiratory flow; MVV, maximal minute ventilation; PT, peak torque. 
Table 5. Relationship between knee flexor and extensor muscle strength and respiratory muscle strength $(n=150)$

\begin{tabular}{lccccc}
\hline \multirow{2}{*}{ Variable } & \multicolumn{2}{c}{ MIP } & & \multicolumn{2}{c}{ MEP } \\
\cline { 2 - 3 } \cline { 5 - 6 } & $r$ & $P$-value & & $P$-value \\
\hline $60^{\circ} /$ sec knee & & & & & \\
Flexion PT & 0.411 & 0.000 & & 0.309 & 0.000 \\
Extension PT & 0.355 & 0.000 & & 0.390 & 0.000 \\
180\% $/$ sec knee & & & & & \\
Flexion PT & 0.356 & 0.000 & & 0.292 & 0.000 \\
Extension PT & 0.348 & 0.000 & & 0.355 & 0.000 \\
\hline
\end{tabular}

MIP, maximum inspiratory pressure; MEP, maximal expiratory pressure; PT, peak torque.

found to be strongly related to each other $(r=0.206 / 0.411, P<$ 0.05) (Table 5).

\section{DISCUSSION}

As a result of our study we found that the athlete's knee flexor and extensor muscle strength and respiratory function were strongly related to each other and knee flexor and extensor muscle strength and respiratory muscle strength were moderately related to each other.

Locomotive functions are provided in the body due to the regulation of skeletal muscle blood flow and the contraction of skeletal muscles. The required energy for muscle contraction is derived from the breakdown of adenosine triphosphate (ATP). The essential feature of the muscular performance ability for continuous periods is the ability to reproduce ATP continuously, even at atmospheric levels (Baker et al., 2010; Sargeant, 1994). For example; During periodic knee extension exercise, quadriceps produces active force when the knee joint comes to the extension, and when the knee joint comes to flexion, the muscle relaxes. At the end and beginning of the contraction, the breakdown rates of ATP change very rapidly depending on the energy requirement. Energy need increases during muscle contraction. When the heart loosens, the energy need decreases. (Andersen et al., 1985; Barclay, 2017). For example, while the ATP concentration in human quadriceps muscles is $\sim 8 \mathrm{mM} / \mathrm{sec}$, the mean ATP turnover in quadriceps muscles increases to $\sim 24 \mathrm{mM} / \mathrm{sec}$ during moderate knee extension exercise (Cannon et al., 2014; Kemp et al., 2007). Oxidative phosphorylation is an important source of ATP during continuous activity. The contracted muscle consumes a large amount of oxygen to fill the ATP that is hydrolyzed during the contraction. For this reason, the circulatory system is closely related to the skeletal muscles in order to provide effective oxygen and nutrient transfer for contraction and for the removal of inhibitory waste products. The skeletal muscles use about $20 \%$ of the cardiac output during the rest, but this rate can increase to $80 \%$ during exercise. The contracted muscle should be able to increase blood flow and oxygen delivery to support metabolic and contractile activities. For this reason, oxygen is a very important factor in the production of energy required for muscle contraction. As the workload increases, the amount of ATP required will increase, and the oxygen requirement will increase accordingly (Korzeniewski, 1998; Simões et al., 2010). Therefore; in athletes who actively use knee flexors and extensor muscles during the competition, we think that lung functions and respiratory muscles develop parallel and support each other in order to provide necessary oxygenation depending on the increase in the strength which needs to be generated due to the workload of these muscles. However, we think that the reason of being a strong relationship between peripheral muscle strength and respiratory functions, and that this relationship is moderately strong in respiratory muscle strength is due to the fact that the athletes have not performed any specific exercise to increase respiratory muscle strength. Because, respiratory muscles can be treated just like skeletal muscles (Pardy and Leith, 1984; Wu et al., 2017). For this reason, we think that as a result of increasing the strength of the respiratory muscles in the athletes may increase the peripheral muscle strength, which is an important parameter of sportive performance.

When we review the literature, it is observed that the studies investigating the relationship between peripheral muscle strength, respiratory function and respiratory muscle strength have been performed in elderly and healthy individuals. Simões et al. (2010) showed that walking distance, respiratory muscle strength and lower extremity muscle strength are related to each other in older individuals. It has been shown by Enright et al. (1994) that the hand gripping force is related to the MIP. Studies of healthy individuals by Ferguson et al. (2001) found that the rate of oxygen uptake and energy cycling during dynamic contractions in an isolated muscle group was greater at 100 repetition frequency than 60 revolutions, muscle blood flow was greater at 100 repetitions and muscle oxygen uptake.

In addition, knee flexor and extensor muscle strength, respiratory muscle strength and respiratory function are parameters related to sportive performance. In the literature, the relationship between knee flexor and extensor muscle strength and sportive performance has been shown in previous studies in the areas where aerobic and anaerobic metabolism are predominantly used; In a study by Soslu et al. (2016) on basketball athletes, maximal knee 
extensor strength was found to be an important component in anaerobic test and sprint performance. Çınar-Medeni et al. (2016) have shown that the strengthening of knee flexor and extensor muscle in orienteering athletes will improve orienting performance. Alemdaroğlu (2012) has shown in their study on basketball athletes that quadriceps muscle strength is related to peak power at all contraction rates. In Newman et al. (2004) study of soccer players, single sprint performance was found to be associated with peak knee extensor and flexor moment at all speeds. In the study of Alexander (1989) in the elite sprinter, the peak isokinetic concentric moment produced by the knee extensor muscles was found to be related to the 100-m performance. Furthermore, in the study of Arslan (2005) in healthy young subjects, explosive leg strength was associated with anaerobic performance. In the study by Salinero et al. (2016), it was concluded that lung function in amateur riders is related to marathon race duration, and that a high lung capacity may be an important variable for marathon performance of amateur runners. Kilding et al. (2010) have shown that inspiratory muscle training improves swimming performance by swimming at $100 \mathrm{~m}$ and $200 \mathrm{~m}$. Nicks et al. (2009) showed that respiratory muscle training improves intermittent exercise performance in soccer players. Pringle et al. (2005) in his study on runners, lung capacity was found to be related to $10-\mathrm{km}$ race performance. Volianitis et al. (2001) have shown that inspiratory muscle training in shovels improves shovel performance. Study by Johnson et al. (1996) on sprints have shown that respiratory muscles limit the performance of high intensity activities such as sprinting. Mador and Acevedo (1991) have shown that inspiratory muscle fatigue, Verges et al. (2007) have shown that expiratory muscle fatigue will disrupt the next exercise performance. Tranchita et al. (2014) have shown that a 4 weeks inspiratuar muscle training protocol bring to improvements in strength and in endurance of respiratory muscles acting on a reduction in respiratory muscle fatigue, delaying restriction metabolic reflex and so giving to skeletal muscles a greater energy availability. In addition, Illi et al. (2012) showed in a systematic review and meta-analysis that respiratory muscle training regardles of type improved the (exercise) performance of healthy individuals. In parallel with this information in the literature, we found that peripheral muscle strength, respiratory function and respiratory muscle strength were related to each other.

In this study, we included athletes from different branches using both aerobic and anaerobic metabolism dominantly. The reason for this was to remove the effects of aerobic and anaerobic metabolisms on respiratory functions. For this reason, there is a need for studies on aerobic and anaerobic metabolism-based athletes which will also be done in regression analysis instead of correlation.

In conclusion, it was determined that the knee flexor and extensor muscular strength, which showed in the literature the effect on sportive performance, correlated with respiratory function and respiratory muscle strength. That's why, we think that the addition of respiratory function and respiratory muscle strength training to the training programs in addition to muscle strength training should be a routine practice in order to improve the sportive performance.

\section{CONFLICT OF INTEREST}

No potential conflict of interest relevant to this article was reported.

\section{REFERENCES}

Alemdaroğlu U. The relationship between muscle strength, anaerobic performance, agility, sprint ability and vertical jump performance in professional basketball players. J Hum Kinet 2012;31:149-158.

Alexander MJ. The relationship between muscle strength and sprint kinematics in elite sprinters. Can J Sport Sci 1989;14:148-157.

American Thoracic Society/European Respiratory Society. ATS/ERS Statement on respiratory muscle testing. Am J Respir Crit Care Med 2002; 166:518-624.

Andersen P, Adams RP, Sjøgaard G, Thorboe A, Saltin B. Dynamic knee extension as model for study of isolated exercising muscle in humans. J Appl Physiol (1985) 1985;59:1647-1653.

Appodia M, Salvati A, Lemme E, Fabrizi E, Todaro A. Verification of the reliability of theoretical spirometric values of the global lung function initiative in elite athletes. Med Sport 2018;71:35-43.

Arikan H, Yatar İ, Calik-Kutukcu E, Aribas Z, Saglam M, Vardar-Yagli N, Savci S, Inal-Ince D, Ozcelik U, Kiper N. A comparison of respiratory and peripheral muscle strength, functional exercise capacity, activities of daily living and physical fitness in patients with cystic fibrosis and healthy subjects. Res Dev Disabil 2015;45-46:147-156.

Arslan C. Relationship between the 30-second wingate test and characteristics of isometric and explosive leg strength in young subjects. J Strength Cond Res 2005;19:658-666.

Baker JS, McCormick MC, Robergs RA. Interaction among skeletal muscle metabolic energy systems during intense exercise. J Nutr Metab 2010;2010:905612.

Barclay CJ. Energy demand and supply in human skeletal muscle. J Mus- 
cle Res Cell Motil 2017;38:143-155.

Cannon DT, Bimson WE, Hampson SA, Bowen TS, Murgatroyd SR, Marwood S, Kemp GJ, Rossiter HB. Skeletal muscle ATP turnover by 31P magnetic resonance spectroscopy during moderate and heavy bilateral knee extension. J Physiol 2014;592:5287-5300.

Çınar-Medeni Ö, Çolakoğlu FF, Yüce K, İpekoğlu G, Baltacı G. The performance measures of orienteers: late adolescents, young adults and adults. Turkiye Klinikleri J Sports Sci 2016;8:1-7.

Enright PL, Kronmal RA, Manolio TA, Schenker MB, Hyatt RE. Respiratory muscle strength in the elderly. Correlates and reference values. Cardiovascular Health Study Research Group. Am J Respir Crit Care Med 1994;149(2 Pt 1):430-438.

Evans JA, Whitelaw WA. The assessment of maximal respiratory mouth pressures in adults. Respir Care 2009;54:1348-1359.

Ferguson RA, Ball D, Krustrup P, Aagaard P, Kjaer M, Sargeant AJ, Hellsten $Y$, Bangsbo J. Muscle oxygen uptake and energy turnover during dynamic exercise at different contraction frequencies in humans. J Physiol 2001;536(Pt 1):261-271.

Illi SK, Held U, Frank I, Spengler CM. Effect of respiratory muscle training on exercise performance in healthy individuals: a systematic review and meta-analysis. Sports Med 2012;42:707-724.

Johnson BD, Aaron EA, Babcock MA, Dempsey JA. Respiratory muscle fatigue during exercise: implications for performance. Med Sci Sports Exerc 1996;28:1129-1137.

Kemp GJ, Meyerspeer M, Moser E. Absolute quantification of phosphorus metabolite concentrations in human muscle in vivo by 31P MRS: a quantitative review. NMR Biomed 2007;20:555-565.

Kilding AE, Brown S, McConnell AK. Inspiratory muscle training improves 100 and $200 \mathrm{~m}$ swimming performance. Eur J Appl Physiol 2010;108:505-511.

Korzeniewski B. Regulation of ATP supply during muscle contraction: theoretical studies. Biochem J 1998;330(Pt 3):1189-1195.

Mador MJ, Acevedo FA. Effect of inspiratory muscle fatigue on breathing pattern during inspiratory resistive loading. J Appl Physiol (1985) 1991;70:1627-1632.

Miller MR, Hankinson J, Brusasco V, Burgos F, Casaburi R, Coates A, Crapo R, Enright P, van der Grinten CP, Gustafsson P, Jensen R, Johnson DC, MacIntyre N, McKay R, Navajas D, Pedersen OF, Pellegrino R, Viegi G, Wanger J; ATS/ERS Task Force. Standardisation of spirometry. Eur Respir J 2005;26:319-338.

Newman MA, Tarpenning KM, Marino FE. Relationships between isoki- netic knee strength, single-sprint performance, and repeated-sprint ability in football players. J Strength Cond Res 2004;18:867-872.

Nicks CR, Morgan DW, Fuller DK, Caputo JL. The influence of respiratory muscle training upon intermittent exercise performance. Int J Sports Med 2009;30:16-21.

Pardy RL, Leith DE. Ventilatory muscle training. Respir Care 1984;29:278284.

Pringle EM, Latin RW, Berg K. The relationship between 10 km running performance and pulmonary function. J Exerc Physiol 2005;8:22-28.

Salinero JJ, Soriano ML, Ruiz-Vicente D, Gonzalez-Millan C, Areces F, Gallo-Salazar C, Abian-Vicen J, Lara B, Del Coso J. Respiratory function is associated to marathon race time. J Sports Med Phys Fitness 2016;56:1433-1438.

Saltin B, Rådegran G, Koskolou MD, Roach RC. Skeletal muscle blood flow in humans and its regulation during exercise. Acta Physiol Scand 1998;162:421-436.

Sargeant AJ. Human power output and muscle fatigue. Int J Sports Med 1994;15:116-121.

Sarsan A, Alkan H, Baser S, Yildiz N, Ozgen M, Ardic F. The effect of aerobic exercise program on pulmonary function and cardiorespiratory capacity in obese women. Turk J Phys Med Reh 2013;59:140-145.

Simões LA, Dias JM, Marinho KC, Pinto CL, Britto RR. Relationship between functional capacity assessed by walking test and respiratory and lower limb muscle function in community-dwelling elders. Rev Bras Fisioter 2010;14:24-30.

Soslu R, Özkan A, Göktepe M. The relationship between anaerobic performances, muscle strength, hamstring/quadriceps ratio, agility, sprint ability and vertical jump in professional basketball players. J Sport Health Sci 2016;10:164-173.

Tranchita E, Minganti C, Musumeci L, Squeo MR, Parisi A. Inspiratory muscles training in young basketball players: preliminary evaluation. Med Sport 2014;67:411-422.

Verges S, Lenherr O, Haner AC, Schulz C, Spengler CM. Increased fatigue resistance of respiratory muscles during exercise after respiratory muscle endurance training. Am J Physiol Regul Integr Comp Physiol 2007;292:R1246-1253.

Volianitis S, McConnell AK, Koutedakis Y, McNaughton L, Backx K, Jones DA. Inspiratory muscle training improves rowing performance. Med Sci Sports Exerc 2001;33:803-809.

Wu CY, Yang TY, Lo PY, Guo LY. Effects of respiratory muscle training on exercise performance in tennis players. Med Sport 2017;70:318-327. 